\title{
LIMITACIONES AL DERECHO DE HUELGA EN CHILE: LOS SERVICIOS ESENCIALES, EL REEMPLAZO DE TRABAJADORES Y LOS SERVICIOS MÍNIMOS EN EL CONTEXTO DE LA REFORMA LABORAL
}

\author{
LIMITATIONS ON THE RIGHT TO STRIKE IN CHILE: \\ ESSENTIAL SERVICES, REPLACEMENT WORKERS AND THE \\ MINIMUM SERVICES IN THE CONTEXT OF LABOR REFORM
}

\author{
RODRIGO AZÓCAR SIMONET* \\ ÁLVARO CRUZ GONZÁLEZ**
}

\begin{abstract}
RESUMEN: No cabe duda que el derecho de huelga es un derecho fundamental, cuyo propósito es garantizar una adecuada protección al ejercicio del derecho de organización que gozan los trabajadores, y sobre todo a la posibilidad que finalmente los trabajadores puedan negociar en un plano de igualdad de condiciones con sus empleadores. Sin embargo, al igual que cualquier derecho reconocido en el ordenamiento jurídico, éste debe confluir e interactuar en el sistema jurídico con diversos derechos, puesto que en un sistema pluralista y democrático no existen derechos absolutos e ilimitados. De esta forma, el derecho de huelga se encuentra afecto a límites y restricciones, mismos que sólo debiesen proceder ante situaciones excepcionales y calificadas, como lo es ante una situación de crisis nacional aguda, o bien cuando se trate de una función pública o de servicios esenciales en el sentido estricto del término.
\end{abstract}

Palabras claves: Huelga, Derecho Fundamental, Servicios esenciales, Servicios minimos, Reemplazo

ABSTRACT: The right to strike is a fundamental right. The purpose is to ensure that there is sufficient protection for organizations that want to organize, especially with the possibility that eventually workers can negotiate on equal conditions with their employers. However, like any right recognized in law, it should merge and interact in the legal system with various rights, since in a pluralistic and democratic systems, limited rights do not exist. Thus, the right to strike is subject to limits and restrictions, these limits \& restrictions can take affect only before extraordinary and authorized situations. For example in a serious national crisis or in the case of public service or essential services, in the strict sense term, limits can occur.

Key words: Strike, Fundamental right, Essential services, Minimun services, Replacement.

\footnotetext{
* Abogado, Licenciado en Derecho de la Facultad de Derecho de la Pontificia Universidad Católica de Chile. Abogado y profesor de Clínica Jurídica especializada en Derecho del Trabajo y Seguridad Social de la Facultad de Derecho de la Pontificia Universidad Católica de Chile. Egresado de Magister de Derecho del Trabajo y de la Seguridad Social, Universidad de Talca y Universidad de Valencia. Correo electrónico reazocar@uc.cl.

** Abogado, Licenciado en Derecho de la Facultad de Derecho de la Pontificia Universidad Católica de Chile. Ayudante del Departamento de Derecho del Trabajo y de la Seguridad Social de la Facultad de Derecho de la Pontificia Universidad Católica de Chile. Egresado de Magister de Derecho del Trabajo y de la Seguridad Social, Universidad de Talca y Universidad de Valencia. Correo electrónico acruzg@uc.cl.
} 


\section{INTRODUCCIÓN}

La libertad sindical supone el reconocimiento, promoción y defensa de tres derechos fundamentales, a saber los derechos de organización, de negociación colectiva y de huelga, constituyendo cada instituto un pilar fundamental que le sirve de sustento y que funcionan como un sistema interconectado, pues su correspondencia hace posible la funcionalidad del derecho colectivo del trabajo y del propio principio de libertad sindical ${ }^{1}$.

Es así como no se puede pretender obtener una eficaz y constructiva negociación colectiva, sin que exista un interlocutor válido, con poder suficiente para equilibrar el funcionamiento de un sistema de relaciones laborales caracterizado por una desigualdad de fuerzas, así como tampoco se puede concebir, por regla general, una organización sindical que no negocie colectivamente. Por otra parte, la actividad de una organización sindical carece de eficacia si no existe un reconocimiento y real ejercicio de la negociación colectiva y de la posibilidad de ejercer el derecho de huelga como un mecanismo de autotutela.

De esta manera, el derecho a huelga es fundamental para la plena vigencia del principio de libertad sindical. Para Oscar Ermida, la huelga constituye "un instituto típico del derecho colectivo que procura efectivizar, precisamente, la autotutela laboral y la libertad sindical".

En efecto, "para que la libertad sindical pueda cumplir su finalidad, no basta que los trabajadores puedan agruparse y formar sindicatos, sino que deben poder equiparar el poder del empleador, para lo cual la concertación colectiva es de vital importancia, y la autotutela colectiva, especialmente la huelga, un elemento esencial's.

En tal sentido, el Comité de Libertad Sindical del Consejo de Administración de la Organización Internacional del Trabajo (en adelante el Comité de Libertad Sindical) ha señalado que el derecho de huelga de los trabajadores y sus organizaciones constituye uno de los medios esenciales de que disponen para promover y defender sus intereses profesionales ${ }^{4}$, transformándose en un corolario indisociable del derecho de sindicación protegido por el Convenio $\mathrm{N}^{\mathrm{o}} 87$ de la Organización Internacional del Trabajo (en adelante OIT). En este contexto, "ha reconocido siempre el derecho de buelga como un derecho legítimo al que pueden recurrir los trabajadores y sus organizaciones en defensa de sus intereses económicos y sociales" 5 .

En el ordenamiento jurídico nacional, la libertad sindical es un derecho elevado a rango constitucional, el cual comprende, por una parte, la facultad de constituir organizaciones

\footnotetext{
${ }^{1}$ En este sentido, Tomás Sala Franco señala que: "La libertad sindical es un concepto ambivalente. La libertad sindical se predica tanto de los trabajadores individualmente considerados, como de los sindicatos ya constituidos. En el primer caso se habla de libertad sindical individual y en el segundo de libertad sindical colectiva, o mejor, de autonomía sindical' (SALA FRANCO, Tomas (2013) p 40). En ese mismo sentido, Oscar Ermida sostiene que la libertad sindical, manifestada en cada uno de sus institutos - libertad de asociación, negociación colectiva y huelga, constituyen una trilogía indisoluble.

${ }^{2}$ ERMIDA (1986) p.9.

3 GAMONAL (2011) p. 366

${ }^{4}$ Recopilación de decisiones y principios del Comité de Libertad Sindical del Consejo de Administración de la OIT. Párrafo 522.

${ }^{5}$ Recopilación de decisiones y principios del Comité de Libertad Sindical del Consejo de Administración de la OIT. Párrafo 521.
} 
sindicales (artículo 19 No 19 de la Constitución Política de la República de Chile, en adelante la Constitución) y, por otra, el derecho a negociar colectivamente (artículo 19 No 16 de la Constitución).

Por su parte, el derecho de huelga, si bien en la Constitución no tiene una consagración expresa, existe cierto grado de consenso, tanto por una parte de la doctrina nacional ${ }^{6}$ como por la jurisprudencia ${ }^{7}$, en señalar que es un derecho constitucional implícito ${ }^{8}$, además de reconocérsele el carácter de derecho fundamental.

A nuestro entender, no cabe duda que el derecho de huelga es un derecho fundamental, cuyo propósito es garantizar una adecuada protección al ejercicio del derecho de organización que gozan los trabajadores, y sobre todo a la posibilidad que finalmente los trabajadores puedan negociar en un plano de igualdad de condiciones con sus empleadores.

No obstante, al igual que cualquier derecho reconocido en el ordenamiento jurídico, éste debe confluir e interactuar con diversos derechos, puesto que en un sistema pluralista y democrático no existen derechos absolutos e ilimitados, de suerte que este derecho se encuentra afecto a determinados límites y restricciones.

Sin perjuicio de lo anterior, cualquier limitación o prohibición que pudiese afectar el derecho de huelga debe interpretarse restrictivamente. En tal sentido, el Comité de Libertad Sindical ha sostenido que la huelga puede ser objeto de restricciones, o incluso de prohibición, sólo ante situaciones excepcionales y calificadas, como lo es ante una situación de crisis nacional aguda, o bien cuando se trate de una función pública o de servicios esenciales en el sentido estricto del término.

Sin considerar la reforma laboral -actualmente en discusión-, nuestra legislación contempla una serie de restricciones, cuya excesiva regulación, a nuestro parecer y a la luz de los lineamientos de los órganos de control de la OIT, ha mermado el legítimo ejercicio del derecho de huelga.

De esta manera, la presente investigación tiene por objeto evaluar críticamente la legislación nacional en relación a las limitaciones o prohibiciones que pueden afectar al derecho de huelga, específicamente en el tratamiento que se ha dado a los servicios esenciales, a los servicios mínimos y al reemplazo de trabajadores, así como analizar los principales cambios que incorporaría la reforma laboral relacionados con el tema central de esta investigación, a la luz de los lineamientos de los órganos de control de la OIT.

De tal modo que, si la legislación contempla la opción de prohibir el reemplazo de trabajadores en buelga, la regulación que se haga del mismo, así como de los servicios esenciales y de los servicios minimos, no puede significar, en la práctica, la posibilidad de mermar la eficacia de

\footnotetext{
${ }^{6}$ Véase "El derecho de huelga en la constitución chilena", GAMONAL CONTRERAS, Sergio. También "Constitución y Orden Público Laboral, Santiago", IRURETA (2006) p.97.

${ }^{7}$ Véase Inspección Comunal del Trabajo Santiago sur Orientge con Comercial Promolinks S.A. (2014)

${ }^{8}$ Fundamentalmente, dado que, la norma constitucional, esto es, el artículo $19 \mathrm{~N}^{\mathrm{o}} 16$ de la Constitución, prohíbe a los funcionarios de la administración del Estado declarar la huelga, pero no se refiere a los demás trabajadores, lo cual, se incluye a la luz de los Tratados Internacionales ratificados y vigentes en Chile.
} 
este derecho o de reemplazar trabajadores en huelga, limitando o haciendo perder eficacia al principal mecanismo de autotutela privilegiado de que disponen los trabajadores.

Para el logro del objetivo propuesto, a modo de introducción y sin pretender agotar la discusión, se analizará el derecho de huelga, luego se determinarán las principales limitaciones a éste, a la luz de la doctrina de los órganos de control de la OIT y las establecidas por la legislación nacional -específicamente en el tratamiento que se ha dado a los servicios esenciales, servicios mínimos y al reemplazo de trabajadores-, valorando críticamente la legislación nacional y analizando aquellos aspectos contemplados en el proyecto de reforma laboral actualmente en discusión.

\section{EL DERECHO DE HUELGA}

El derecho de huelga y su reconocimiento por parte de los Estados, ha evolucionado desde diferentes estadios. En una primera etapa se concibe la huelga como un delito, luego es tolerada, y finalmente es reconocida como un derecho?

En efecto, en la primera etapa, la huelga se concibe como una perturbación general de la paz social, prohibiéndose el conflicto y penalizándose su ejercicio. Luego, la actitud del Estado no será de persecución, sino de tolerancia, al calificarse el ejercicio de la huelga como un incumplimiento contractual, que podía implicar, por una parte, el despido de trabajadores, así como, la indemnización de daños a favor del empleador. Finalmente, "en una tercera etapa, ubicada a partir de la segunda posguerra, la buelga comienza a ser considerada como un derecho, y el Estado comienza a tutelar los intereses y derechos de los grupos intermedios que funcionan entre el individuo y el Estado" 10 .

Siguiendo esta evolución, si bien en la Constitución la huelga no tiene una consagración expresa, existe cierto grado de consenso, tanto por una parte de la doctrina nacional ${ }^{11}$ como por la jurisprudencia ${ }^{12}$, en sostener que es un derecho constitucional implícito ${ }^{13}$, además de reconocérsele el carácter de derecho fundamental.

Reconocimiento que se funda, entre otras consideraciones, indirectamente, en el contenido del derecho de la libertad sindical, consagrado tanto en la Constitución ${ }^{14}$ como en los Convenios No 87 y 98 de la OIT, y particularmente en el Pacto de Derechos Económicos, Sociales y Culturales, el cual reconoce expresamente en su artículo $8^{\circ}$ el derecho a la huelga. De esta manera, es un derecho que explícita e implícitamente ha sido reconocido y protegido por

\footnotetext{
${ }^{9}$ SALA (2013) p. 328.

${ }^{10}$ MANTERO (1992) p.20.

11 Véase "El derecho de huelga en la constitución chilena", GAMONAL (2013). También "Constitución y Orden Público Laboral, Santiago", IRURETA (2006) p.97.

12 Véase Inspección Comunal del Trabajo Santiago sur Orientge con Comercial Promolinks S.A. (2014)

${ }^{13}$ Fundamentalmente, dado que, la norma constitucional, esto es, el artículo $19 \mathrm{~N}^{\mathrm{o}} 16$ de la Constitución, prohíbe a los funcionarios de la administración del Estado declarar la huelga, pero no se refiere a los demás trabajadores, lo cual, se incluye a la luz de los Tratados Internacionales ratificados y vigentes en Chile.

${ }^{14}$ Artículo $\mathrm{N}^{\mathrm{o}} 19 \mathrm{~N}^{\mathrm{o}} \mathrm{s} 16$ y 19 de la Constitución.
} 
la Constitución y por los Tratados Internacionales de Derechos Humanos ratificados por Chile y que se encuentran vigentes ${ }^{15}$.

Por otra parte, en nuestro ordenamiento jurídico nacional la huelga no ha sido definida, sino sólo se ha regulado en el proceso de negociación colectiva, y particularmente se ha enmarcado su ejercicio dentro de uno de los tres procedimientos regulados en nuestra legislación ${ }^{16}$.

Ante tal ausencia, y de manera restrictiva, una parte de la doctrina nacional y de la jurisprudencia ha circunscrito este derecho únicamente dentro del proceso de negociación colectiva. Así, se ha definido la huelga como la "abstención concertada de trabajar, que ejecuta un sindicato o un grupo de trabajadores, dentro de un periodo limitado y con los requisitos legales, con el propósito de persuadir a su respectivo empleador para la suscripción de un contrato colectivo" ${ }^{17}$.

Sin embargo, esta concepción restrictiva puede ser superada por una interpretación sistemática de nuestro ordenamiento jurídico nacional que, en virtud del inciso segundo del artículo 5 de la Constitución, eleve a rango constitucional los Tratados Internacionales de Derechos Humanos ratificados por Chile y que se encuentran vigentes, reconociendo y protegiendo este derecho fundamental incluso fuera del proceso de negociación colectiva.

Bajo tal sentido interpretativo, la Iltma. Corte de Apelaciones de Santiago en causa Actionline Chile S.A. con Yutronic (2015) ha sostenido que la huelga es un derecho fundamental, que se sustenta en tratados internacionales de derechos humanos y en la Constitución. Agrega, además, que la sola circunstancia que la ley regule la huelga para un caso (negociación colectiva reglada) no puede llevar a concluir que fuera de ella se encuentre prohibida, pues lo que el legislador ha omitido regular o definir, no puede sostenerse que lo ha prohibido. A su vez, sostiene que los límites al derecho fundamental de huelga están dados únicamente cuando se afectan servicios destinados a satisfacer derechos fundamentales, libertades públicas y bienes constitucionalmente protegidos, tales como la vida, la salud y la satisfacción de necesidades básicas de la persona, lo que, como toda limitación o restricción de derechos fundamentales, debe regularse por ley, sin afectar el derecho en su esencia.

\footnotetext{
${ }_{15} \mathrm{Al}$ respecto, especial consideración merecen la ratificación de los convenios $\mathrm{N}^{\mathrm{o}} 87$ y 98 de la OIT, el Pacto Internacional de Derechos Económicos, Sociales y Culturales y el Protocolo Adicional a la Convención Americana sobre Derechos Humanos en Materia de Derechos Económicos, Sociales y Culturales, entre otros.

En efecto, el Pacto Internacional de Derechos Económicos, Sociales y Culturales, acordado por las Naciones Unidas en 1966, suscrito por Chile el 16 de septiembre de 1969 y promulgado por Decreto $\mathrm{N}^{\circ} 326$ de 27 de mayo de 1989, consagra en su artículo $8 \mathrm{~N}^{\circ}$ 1, letra d), que los Estados partes en el presente pacto se comprometen a garantizar "el derecho de huelga, ejercido de conformidad con las leyes de cada país".

Agrega el referido Pacto, que nada de lo dispuesto en este artículo autorizará a los Estados partes en el Convenio de la OIT de 1948 relativo a la libertad sindical y protección del derecho de sindicación, a adoptar las medidas legislativas que menoscaben las garantías previstas en dicho Convenio o a aplicar la ley en forma que menoscabe dichas garantías (artículo $8 \mathrm{~N}^{\circ}$ 3).

Por su parte, el Comité de libertad Sindical de la OIT, siempre ha considerado el derecho de huelga como constitutivo de los derechos básicos de los trabajadores y sus organizaciones en la defensa de sus intereses laborales.

16 Negociación colectiva reglada (artículos 325 y siguientes del Código del Trabajo); Negociación colectiva no reglada (artículo 314 Código del Trabajo); Negociación semi-reglada (artículo 314 Bis).

${ }^{17}$ MACCHIAVELLO (1989) p. 445.
} 
Finalmente, a la luz de tales argumentos, concluye que la tesis de que la huelga era una etapa indeseable ha sido superada.

En el mismo sentido, la doctrina laboral comparada entiende la huelga "como cualquier interrupción colectiva de la normalidad productiva en la empresa, con la finalidad que los propios trabajadores determinen. En palabras de Plá "toda interrupción o alteración del trabajo, con finalidad de protesta gremial, está dentro de la definición de huelga y debe ser considerada lícita, con la única excepción del sabotaje" ${ }^{\text {"18. }}$.

Asimismo, Sala Franco, tras señalar que la huelga tradicionalmente se ha entendido como la cesación temporal del trabajo decidida por una colectividad de trabajadores con abandono del centro de trabajo, con motivo de un conflicto y con el fin de presionar en la defensa de sus intereses, ha planteado que dicha concepción viene extendida modernamente a todo tipo de perturbación, de las que la cesación del trabajo con abandono de centro sería seguramente la más paradigmática, pero que no excluye a otras ${ }^{19}$.

También la OIT, a través de sus diferentes instrumentos y órganos de control, ha dado una interpretación amplia del derecho de huelga, al establecer que "algunas modalidades (como la ocupación del centro de trabajo o el centro a ritmo lento o las huelgas de celo), que no se limitan a la típica interrupción de labores, han sido aceptadas por el Comité de libertad Sindical siempre y cuando revistan carácter pacifico" $^{20}$.

En efecto, según la Comisión de Expertos en Aplicación de Convenios y Recomendaciones de la OIT (en adelante la Comisión de Expertos), "cuando la legislación nacional garantiza el derecho de huelga, muy a menudo se plantea el problema de determinar si la acción comprendida por los trabajadores efectivamente constituye una buelga de conformidad con la definición contenida en la ley. En general cabe considerar como buelga toda suspensión del trabajo, por breve que sea ésta; ahora bien, establecer esta calificación resulta menos fácil cuando, en lugar de producirse una cesación absoluta de la actividad, se trabaja con mayor lentitud (buelga de trabajo a ritmo lento) o se aplica el reglamento al pie de la letra (buelga de celo o trabajo a reglamento); tratarse en ambos casos de buelgas que tienen efectos tan paralizantes como la suspensión radical del trabajo. Observando que las legislaciones y las prácticas nacionales son extremadamente variadas sobre este punto, la Comisión estima que las restricciones en relación a los tipos de buelgas sólo se justificarian si la buelga perdiere su carácter pacifico" ${ }^{21}$.

En el mismo sentido, el Comité de Libertad Sindical ha expresado que "en cuanto a las modalidades del derecho a buelga denegado a los trabajadores (paralización intempestiva, huelga a reglamento, buelga de brazos caídos, huelga de celo, trabajo a ritmo lento, ocupación de la empresa o centro de trabajo) el Comité considera que tales limitaciones sólo se justificarían en los casos en que la buelga dejase de ser pacifica" 22 .

Sin perjuicio de las distintas visiones planteadas, a nuestro entender, no cabe duda ni discusión que, al menos, el derecho de huelga constituye un derecho fundamental dentro del

${ }^{18}$ UGARTE (2014) La buelga en el derecho laboral chileno: superando el espejismo.

${ }^{19}$ SALA (2013) pp. 327-328.

${ }^{20}$ GERNIGON; ODERO y GUIDO (1998) p. 12.

${ }^{21}$ GERNIGON; ODERO y GUIDO (1998) p. 12.

${ }^{22}$ Véase Recopilación de 1996, párrafos 496 y 497 y 306. informe, caso núm. 1865, párrafo 337. 
proceso de negociación colectiva y, como tal, debe ser considerado un medio legítimo y de última ratio que gozan los trabajadores, cuyo propósito principal es dar eficacia a la promoción y defensa de sus intereses, que explícita e implícitamente ha sido reconocido y protegido por la Constitución y por los Tratados Internacionales de Derechos Humanos ratificados por Chile y que se encuentran vigentes.

\section{RESTRICCIONES O PROHIBICIONES AL DERECHO DE HUELGA}

Tratándose de un derecho de carácter fundamental, a nuestro entender, la huelga requiere de un reconocimiento y garantía total, puesto que cualquiera sea la limitación o restricción que pueda afectarla, éstas generan una pérdida de eficacia en su ejercicio. Sin embargo, entendemos que la huelga, al igual que cualquier derecho inserto en un sistema pluralista y democrático, requiere ser armonizado con otros derechos fundamentales de ciudadanos y empleadores, dado que "la presencia de derechos absolutos e ilimitados, no parece compatible con un Estado pluralista y democrático"23.

Al respecto, Valdés del Re, a quien hace referencia Ricardo Mantero ${ }^{24}$, sostiene que "desde el momento en que la buelga se instrumenta como derecho y sobre ella opera la disciplina jurídica pasa a encuadrarse necesariamente en el ordenamiento general que garantiza su ejercicio dentro de ciertos límites. Asi enunciado, el principio es indiscutido; si todo derecho nace con su límite, el derecho de huelga no constituye excepción, esto es, no es una expresión de una libertad plena y absoluta".

Respecto a este tema, Oscar Ermida Uriarte, ha planteado que "entre los tantos límites que se proponen o se inventan respecto del derecho de buelga, el de la perseveración de la continuidad de los servicios esenciales para la comunidad, es el único que posee una estatura comparable a la del derecho de buelga y por tanto suficiente para pretender erigirse en un límite u obstáculo para su ejercicio"25.

Sin perjuicio de lo anterior, tanto la Comisión de Expertos como el Comité de Libertad Sindical, han señalado reiteradamente que cualquier limitación o restricción que pudiese afectar el ejercicio del derecho de huelga, sólo proceden ante situaciones excepcionales y calificadas, las que deben interpretarse restrictivamente ${ }^{26}$.

En efecto, el Comité de Libertad Sindical ha establecido que la huelga puede ser objeto de restricciones, o incluso de prohibición, únicamente ante una situación de crisis nacional aguda, o bien cuando se trate de las fuerzas armadas y de la policía, así como también cuando se trate de la función pública que realizan actos de autoridad en nombre del Estado o de los trabajadores de los servicios esenciales en el sentido estricto del término. Vale decir, sólo contempla dicha posibilidad ante situaciones excepcionales y calificadas.

De esta manera, el mismo Comité de Libertad Sindical ha establecido que "el derecho de buelga puede ser objeto de restricciones, incluso de probibiciones, cuando se trate de la función pública o de

\footnotetext{
${ }^{23}$ MANTERO (1992) p. 17.

${ }^{24}$ MANTERO (1992) p. 17.

${ }^{25}$ Revista derecho laboral, tomo XLVI, No 211, julio-septiembre 2033, pág. 519, Uruguay.

${ }^{26}$ OIT, 1994a, párrafos 159 y 160.
} 
servicios esenciales, en la medida en que la huelga pudiere causar graves perjuicios a la colectividad nacional y a condición de que estas restricciones vayan acompañadas de ciertas garantías compensatorias" ${ }^{27}$.

No obstante lo señalado, la regulación que el Código del Trabajo chileno ha dado al derecho de huelga, aún con las modificaciones que se han incorporado ${ }^{28}$, se ha caracterizado por su rigidez, tal es ésta, que sólo se reconoce su legítimo ejercicio en el procedimiento de negociación colectiva reglado (artículo 379 y sgtes. del Código del Trabajo), omitiendo regulación respecto a su uso en cualquier otro conflicto colectivo que pudiese surgir de una relación laboral u a otras modalidades que no sea la suspensión de labores.

Asimismo, se establecen una serie de restricciones, entre ellas, cabe señalar, por una parte, la facultad que detentan los empleadores de contratar trabajadores de reemplazo, y por otra, las limitaciones que afectan a aquellos trabajadores que se desempeñan en actividades de la administración del Estado, así como los servicios mínimos y los servicios esenciales.

Pues bien, dado el impacto que dichas restricciones generan en el ejercicio del derecho de huelga, a continuación, abordaremos de un modo descriptivo y crítico la regulación que se ha dado en Chile a los servicios esenciales, a los servicios mínimos y al reemplazo de trabajadores, y cómo dichas instituciones han sido abordadas por los órganos de control de la OIT. Asimismo, se analizará el proyecto de reforma laboral actualmente en discusión, y su concordancia con los lineamientos de los referidos órganos de control.

\section{LOS SERVICIOS ESENCIALES}

\subsection{LOS SERVICIOS ESENCIALES EN LA DOCTRINA DE LA OIT}

La OIT, a través de sus órganos de control, ha entendido que los servicios esenciales corresponden a aquellos "servicios cuya intermpción podría poner en peligro la vida, la seguridad o la salud

\footnotetext{
${ }^{27}$ Recopilación de decisiones y principios del Comité de Libertad Sindical del Consejo de Administración de la OIT. Párrafo 573.

28 Los principales cuerpos normativos que, en el último tiempo, han regulado el reemplazo de trabajadores en huelga, datan de 1979. En primer lugar, cabe señalar el Decreto Ley $\mathrm{N}^{\circ}$ 2758, fundante del Plan Laboral promovido durante el Régimen Militar, ley que en su artículo 58, inciso segundo, prescribía que "...durante la buelga el empleador seguirá administrando la empresa y realizando cualquier función o actividad propia de ella, para cuyo efecto podrá contratar los trabajadores que considere necesario".

Posteriormente, en 1991, se publica la ley N 19.069 , que establece normas sobre Organizaciones Sindicales y Negociación Colectiva, prescribiendo en su artículo 157, que "El empleador podrá contratar a los trabajadores que considere necesarios para el desempeño de las funciones de los involucrados en la buelga, a partir del primer día de baberse hecho ésta efectiva...", en la medida que se hubiese dado cumplimiento a las condiciones previstas en las letras a) y b) del actual artículo 381 del Código del Trabajo.

Finalmente, durante el año 2001 se publica la ley No 19.759, modificatoria del Código del Trabajo, la cual incorpora al inciso primero del actual artículo 381 de dicho Código, una referencia de carácter impeditivo del reemplazo. En efecto se establece que "Estará probibido el reemplazo de los trabajadores en huelga".

Cabe señalar que actualmente se discute un proyecto de ley que modifica partes importantes del derecho de huelga, como lo son el reemplazo en la misma y el concepto de servicios esenciales.
} 
de la persona en toda o en parte de la población" 29 . En este sentido, "el criterio determinante es la existencia de una amenaza evidente e inminente para la vida, la seguridad o la salud de toda o parte de la población"30.

La determinación de estos servicios debe ser realizada de manera restrictiva dependiendo del contexto y condiciones particulares de cada país, no pudiendo realizar generalizaciones y debiendo analizarse caso a caso ${ }^{31}$. De esta manera, "lo que se entiende por servicios esenciales en el sentido estricto de la palabra depende en gran medida de las condiciones propias de cada pais" 32 .

Asimismo, ha señalado que un servicio no esencial puede convertirse en uno esencial cuando sobrepasa cierto periodo de tiempo en duración o cierto alcance, siempre y cuando tenga los efectos antes señalados ${ }^{33}$. Esto ocurre, por ejemplo, en el caso del servicio de recolección de basuras, el que "puede convertirse en esencial si la buelga que repercute a este servicio dura más de un cierto periodo o adquiere tal dimensión que puede correr peligro la salud o la vida de la población" 34 .

También ha expresado que se atenta contra el concepto mismo de servicios esenciales si se trata de calificar como tales a aquellas situaciones que no cumplen con los criterios que le son propios. Tal es el caso de las huelgas que impliquen consecuencias graves a largo plazo para la economía nacional, si existe una definición amplia del concepto de servicios esenciales en la legislación, o si el gobierno tiene facultades discrecionales para ampliar la lista de empresas que se consideran como servicios esenciales.

Ahora bien, dado que los trabajadores afectados con las limitaciones o prohibiciones al derecho de huelga a través de los servicios esenciales pierden uno de los derechos y medios fundamentales para promover y defender sus intereses, el mismo Organismo ha indicado que deben disfrutar de una protección compensatoria, como lo son los mecanismos de conciliación, mediación y arbitraje. En este sentido, "cuando el derecho de huelga ha sido limitado o suprimido en empresas o servicios considerados esenciales, los trabajadores deben gozar de una protección adecuada, de suerte que se les compensen las restricciones impuestas a su libertad de acción durante los conflictos que puedan surgir en dichas empresas o servicios" 35 .

De esta manera, "la limitación de la huelga debe ir acompañada por procedimientos de conciliación y arbitraje adecuados, imparciales y rápidos en que los interesados puedan participar en todas las etapas, y en los que los laudos dictados deberían ser aplicados por completo y rápidamente”36.

29 OIT, 1983b, párrafo 214.

${ }^{30}$ Recopilación de decisiones y principios del Comité de Libertad Sindical del Consejo de Administración de la OIT. Párrafo 581.

${ }^{31}$ Recopilación de decisiones y principios del Comité de Libertad Sindical del Consejo de Administración de la OIT. 1994a, párrafos 159 y 160.

32 Recopilación de decisiones y principios del Comité de Libertad Sindical del Consejo de Administración de la OIT. Párrafo 582.

${ }^{33}$ Recopilación de decisiones y principios del Comité de Libertad Sindical del Consejo de Administración de la OIT. Párrafo 582.

${ }^{34}$ Recopilación de decisiones y principios del Comité de Libertad Sindical del Consejo de Administración de la OIT. Párrafo 591.

${ }^{35}$ Recopilación de decisiones y principios del Comité de Libertad Sindical del Consejo de Administración de la OIT. Párrafo 595.

${ }^{36}$ Recopilación de decisiones y principios del Comité de Libertad Sindical del Consejo de Administración de la OIT. Párrafo 596. 
Finalmente, el Comité de Libertad Sindical ha establecido que pueden ser considerados como servicios esenciales, entre otros ${ }^{37}$, el sector hospitalario, los servicios de electricidad, los servicios de abastecimiento de agua, los servicios telefónicos, la policía y las fuerzas armadas, los servicios penitenciarios públicos o privados, el suministro de alimentos a los alumnos en edad escolar, la limpieza de los establecimientos escolares y el control del tráfico aéreo ${ }^{38}$.

\subsection{LOS SERVICIOS ESENCIALES EN CHILE}

Ya desde la Constitución se reconoce y recoge la idea de servicios esenciales. Es así como en el artículo $19 \mathrm{~N}^{\circ} 16$ se establece que no pueden declararse en huelga las personas que trabajen en corporaciones o empresas, cualquiera que sea su naturaleza, finalidad o función, que atiendan servicios de utilidad pública o cuya paralización cause grave daño a la salud, a la economía del país, al abastecimiento de la población o a la seguridad nacional. Asimismo, se establece que corresponde a la ley establecer los procedimientos para determinar las corporaciones o empresas cuyos trabajadores deben someterse a la prohibición de declararse en huelga.

A su vez, el Código del Trabajo, en su artículo 384, establece que los trabajadores de las empresas cuya paralización que por su naturaleza cause grave daño a la salud, al abastecimiento de la población, a la economía del país o a la seguridad nacional no pueden declarar la huelga, siempre y cuando comprenda parte significativa de la actividad respectiva del país, o cuya paralización implique la imposibilidad total de recibir un servicio para un sector de la población.

De esta manera, a la luz de la doctrina de los órganos de control de la OIT antes analizada, se advierte que a través de esta prohibición amplia de ejercer la huelga, el concepto que utiliza nuestra legislación respecto a los servicios esenciales abarca otros servicios que van más allá de aquél cuya interrupción podría poner en peligro la vida, la seguridad o la salud de la persona, en toda o en parte de la población nacional.

En el ordenamiento jurídico nacional se contempla como protección compensatoria a estos trabajadores que si las partes en el proceso de negociación colectiva no logran acuerdo directo, se deban someter a un arbitraje obligatorio que regula la ley, con las consecuencias que

\footnotetext{
${ }^{37}$ Recopilación de decisiones y principios del Comité de Libertad Sindical del Consejo de Administración de la OIT. Párrafo 587.

38 A su vez, el mismo órgano de control de la OIT ha señalado que no constituyen servicios esenciales en el sentido estricto del término: la radio-televisión, los sectores del petróleo, los puertos (carga y descarga), los bancos, los servicios de informática para la recaudación de aranceles e impuestos, los grandes almacenes y los parques de atracciones, la metalurgia y el conjunto del sector mineros, los transportes en general, los pilotos de líneas aéreas, la generación, transporte y distribución de combustibles, los servicios ferroviarios, los transportes metropolitanos, los servicios de correos, el servicio de recolección de basuras, las empresas frigoríficas, los servicios de hotelería, la construcción, la fabricación de automóviles, las actividades agrícolas, el abastecimiento y la distribución de productos alimentarios, la Casa de la Moneda, la Agencia Gráfica del Estado y los monopolios estatales del alcohol, de la sal y del tabaco.
} 
de ello se derivan ${ }^{39}$. Cabe señalar que dicho mecanismo de resolución de conflicto tiene una escasa, por no decir nula, aplicación.

En cuanto a la calificación de las empresas cuyos trabajadores no pueden declarar la huelga, ésta es realizada dentro del mes de julio de cada año, por resolución conjunta de los Ministros del Trabajo y Previsión Social, Defensa Nacional y Economía, Fomento y Reconstrucción ${ }^{40}$.

Esta calificación a través de la autoridad administrativa -con todo lo que ello significaha sido objeto de distintos pronunciamientos y observaciones por parte de la Comisión de Expertos $^{41}$, ya que existe una contradicción entre los estándares internacionales y la normativa nacional, toda vez que la lista que elabora el Gobierno es demasiado amplia y contempla servicios que su interrupción, en términos de los órganos de control de la OIT, no pueden producir peligro a la vida, la seguridad o la salud de la persona, en toda o parte de la población. De esta manera, no es congruente con el concepto de servicios esenciales en sentido estricto del término.

Conforme a las últimas indicaciones ingresadas por el Ejecutivo al proyecto de ley que moderniza el sistema de relaciones laborales ${ }^{42}$, se plantea un procedimiento para la determinación de las empresas en las que no se podrá ejercer el derecho a huelga.

En efecto, se establece que no podrán declarar la huelga los trabajadores que presten servicios en corporaciones o empresas, cualquiera sea su naturaleza, finalidad o función, que atiendan servicios de utilidad pública o cuya paralización cause grave daño a la salud, a la economía del país, al abastecimiento de la población o a la seguridad nacional.

En cuanto a la calificación de encontrarse la empresa en alguna de las situaciones señaladas en este artículo, será efectuada cada dos años, dentro del mes de julio, por resolución conjunta de los Ministros del Trabajo y Previsión Social, Defensa Nacional y Economía, Fomento y Turismo, previa solicitud fundada de parte, la que deberá presentarse hasta el 31 de mayo del año respectivo. Promovida la solicitud, se pondrá en conocimiento de la contraparte empleadora o trabajadora para que formule las observaciones que estime pertinentes, dentro del plazo de 15 días.

A su vez, efectuada la calificación de una empresa e incorporada en la resolución conjunta respectiva, sólo por causa sobreviniente y a solicitud de parte se podrá revisar su permanencia. La resolución deberá publicarse en el Diario Oficial y se establece que podrá ser reclamada ante la Corte de Apelaciones.

\footnotetext{
39 Conforme a lo previsto en el artículo 363 del Código del Trabajo, el Tribunal arbitral, en caso de arbitrajes obligatorios, estará obligado a fallar a favor de una de las dos proposiciones de las partes, vigente al momento de someterse el caso a arbitraje, debiendo ésta aceptarse en su integridad.

${ }^{40}$ La última resolución administrativa corresponde a la Resolución Exenta $N^{\circ} 123$, de fecha 29.07.2015, la que incluye una serie de empresas y establecimientos como lo son: ferrocarriles, puertos, electricidad, sanitarias, gas, entre otros.

${ }^{41}$ Entre ellos, se encuentran los casos N²135 del año 2001 y N²649 del año 2009.

42 Indicaciones al proyecto de ley que moderniza el sistema de relaciones laborales, introduciendo modificaciones al Código del Trabajo. Boletín 9835-2013, de 12.09. 2015. Nº 935-363.
} 
Respecto a las últimas indicaciones ingresadas por el Ejecutivo al proyecto de ley que moderniza el sistema de relaciones laborales, en los términos planteados, si bien presenta avances en algunos aspectos, conforme a lo expuesto en párrafos precedentes, no es completamente coherente con los lineamientos planteados por los órganos de control de la OIT.

\section{LOS SERVICIOS MÍNIMOS}

\subsection{LOS SERVICIOS MÍNIMOS EN LA DOCTRINA DE LA OIT}

Los servicios esenciales, en el sentido estricto del término, difiere del concepto de servicios mínimos. Este último tiene por finalidad asegurar el mantenimiento de servicios que durante la huelga garanticen la cobertura de las necesidades básicas de la población, el funcionamiento continuo o en condiciones de seguridad de las instalaciones, con lo cual si bien no se prohíbe el derecho de huelga, si se impone la necesidad de contar con un servicio mínimo de funcionamiento de la empresa o de la institución respectiva.

Al respecto, el Comité de Libertad Sindical ha establecido la posibilidad de establecer un servicio mínimo de seguridad para garantizar la seguridad de las personas y las instalaciones de la empresa. En este sentido, ha considerado admisible las limitaciones al derecho de huelga en el caso de "una legislación que obligaba a las organizaciones profesionales de todas las actividades a procurar que siga prestando sus servicios el personal necesario para la seguridad de las instalaciones y la prevención de accidentes, previéndose que las divergencias que puedan surgir con respecto a este personal deben ser zanjadas por el tribunal administrativo de arbitraje" ${ }^{43}$.

A su vez, también ha considerado admisible la posibilidad que se imponga un servicio minimo de funcionamiento, el cual "podría ser una solución sustitutiva apropiada de la probibición total, en las situaciones en que no parece justificada una limitación importante o la probibición total de la buelga y en que, sin poner en tela de juicio el derecho de buelga de la gran mayoría de los trabajadores, podría tratarse de asegurar la satisfacción de las necesidades básicas de los usuarios o el funcionamiento continuo y en condiciones de seguridad de las instalaciones" ${ }^{\prime 4}$.

Sin perjuicio de lo anterior, ha estimado que los servicios mínimos deben limitarse a las operaciones estrictamente necesarias ${ }^{45}$ y aplicarse de manera estricta, junto con ser determinadas en forma clara y ser conocidas con la debida anticipación ${ }^{46}$.

\footnotetext{
43 Recopilación de decisiones y principios del Comité de Libertad Sindical del Consejo de Administración de la OIT. Párrafo 605.

${ }^{44}$ Recopilación de decisiones y principios del Comité de Libertad Sindical del Consejo de Administración de la OIT. Párrafo 607.

${ }^{45}$ En esta línea argumentativa, el Comité de Libertad Sindical ha estimado que "un servicio minimo puede establecerse en casos de huelgas cuya extensión y duración pudieran provocar una situación de crisis nacional aguda tal que las condiciones normales de existencia de la población podrían estar en peligro; para ser aceptable, dicho servicio mínimo debería limitarse a las operaciones estrictamente necesarias para no comprometer la vida o las condiciones normales de existencia de toda o parte de la población y debería posibilitar, por otra parte, en lo que se refiere a su determinación, la participación de las organizaciones de trabajadores así como de los empleadores y de las autoridades públicas" (Recopilación de decisiones y principios del Comité de Libertad Sindical del Consejo de Administración de la OIT. Párrafo 610).

${ }^{46}$ De esta manera, "el Comité ha insistido en la importancia de que las disposiciones relativas a los servicios minimos a aplicar en caso de buelga en un servicio esencial se determinen en forma clara, se apliquen estrictamente y sean conocidas a su debido tiempo por
} 
En cuanto a la participación en la definición de los servicios mínimos, el Comité de Libertad Sindical ha estimado que deben participar tanto las autoridades públicas como las organizaciones de los trabajadores y de los empleadores ${ }^{47}$. A su vez, en caso de divergencia, ésta debe ser resuelta por un órgano independiente y no por una autoridad pública o administrativa ${ }^{48}$.

Algunos ejemplos concretos en que el mismo Comité de Libertad Sindical ha considerado que concurrían las circunstancias para imponer un servicio mínimo de funcionamiento, pese a que estas actividades no corresponden a un servicio esencial en el sentido estricto del término, son: servicio de transbordadores ${ }^{49}$, sector portuario ${ }^{50}$, servicios de transporte subterráneos o metro $^{51}$, transporte ferroviario ${ }^{52}$, transporte de pasajeros y mercancías ${ }^{53}$, servicios de $\operatorname{correos}^{54}$, recolección de basuras ${ }^{55}$, sector de la educación ${ }^{56}$, los bancos, los transportes y los sectores del petróleo ${ }^{57}$.

\subsection{LOS SERVICIOS MÍNIMOS EN CHILE}

los interesados" (Recopilación de decisiones y principios del Comité de Libertad Sindical del Consejo de Administración de la OIT. Párrafo 611).

${ }^{47}$ En este sentido, el Comité de Libertad Sindical ha considerado que "es legítimo requerir un servicio mínimo en caso de una huelga cuya magnitud y duración pudieran provocar una situación de crisis nacional aguda, pero en este último caso las organizaciones sindicales deberían poder participar en su definición, junto con los empleadores y las autoridades públicas" (Recopilación de decisiones y principios del Comité de Libertad Sindical del Consejo de Administración de la OIT. Párrafo 609). Asimismo, "en la determinación de los servicios mínimos y del número de trabajadores que los garanticen deberían poder participar no sólo las autoridades públicas, sino también las organizaciones de trabajadores y de empleadores interesadas. En efecto, ello no sólo permite un ponderado intercambio de puntos de vista sobre lo que en una situación concreta puede considerarse como servicios mínimos limitados a lo estrictamente indispensable, sino que también contribuye a garantizar que el alcance de los servicios mínimos no tenga por resultado que la buelga sea inoperante en la práctica en razón de su escaso impacto, así como a disipar posibles impresiones de las organizaciones sindicales en el sentido de que una acción de buelga se ha visto frustrada en razón de servicios mínimos concebidos demasiado ampliamente y fijados unilateralmente" (Recopilación de decisiones y principios del Comité de Libertad Sindical del Consejo de Administración de la OIT. Párrafo 612).

${ }^{48}$ Recopilación de decisiones y principios del Comité de Libertad Sindical del Consejo de Administración de la OIT. Párrafos 613 y 614.

49 Recopilación de decisiones y principios del Comité de Libertad Sindical del Consejo de Administración de la OIT. Párrafo 615.

50 Recopilación de decisiones y principios del Comité de Libertad Sindical del Consejo de Administración de la OIT. Párrafo 616.

${ }^{51}$ Recopilación de decisiones y principios del Comité de Libertad Sindical del Consejo de Administración de la OIT. Párrafo 617.

${ }^{52}$ Recopilación de decisiones y principios del Comité de Libertad Sindical del Consejo de Administración de la OIT. Párrafo 619.

${ }^{53}$ Recopilación de decisiones y principios del Comité de Libertad Sindical del Consejo de Administración de la OIT. Párrafo 621.

${ }^{54}$ Recopilación de decisiones y principios del Comité de Libertad Sindical del Consejo de Administración de la OIT. Párrafo 622.

${ }_{55}$ Recopilación de decisiones y principios del Comité de Libertad Sindical del Consejo de Administración de la OIT. Párrafo 623.

${ }^{56}$ Recopilación de decisiones y principios del Comité de Libertad Sindical del Consejo de Administración de la OIT. Párrafo 625.

${ }^{57}$ Recopilación de decisiones y principios del Comité de Libertad Sindical del Consejo de Administración de la OIT. Párrafo 624. 
Bajo la actual legislación ${ }^{58}$, durante la huelga y a fin de mantener la continuidad de aquellas actividades cuya paralización pudiese causar un daño irreparable en los bienes materiales o la salud de los usuarios de un establecimiento asistencial o de salud o que preste servicios esenciales, los trabajadores se encuentran obligados a proporcionar el personal indispensable -equipos de emergencia- para la ejecución de aquellas actividades cuya paralización pudiese causar el referido daño.

A fin de hacer efectiva dicha facultad, el empleador debe requerir por escrito a la comisión negociadora los trabajadores que conformarán los equipos de emergencia, en cuyo caso, la comisión negociadora dispondrá de un plazo de 24 horas para responder dicho requerimiento.

Ahora bien, si la comisión negociadora se niega a proporcionar los equipos de emergencia solicitados, o existe discrepancia en cuanto a la composición de estos, el empleador, dentro de un plazo de 5 días contados desde la fecha de negativa de los trabajadores o de la falta de acuerdo, puede reclamar de ésta ante la Inspección del Trabajo a fin de que se pronuncie sobre la obligación que asiste a los trabajadores de proporcionar dicho equipo. Institución que dentro de un plazo de 48 horas debe resolver dicha solicitud.

De dicha resolución, las partes pueden reclamar ante el Juzgado de Letras del Trabajo dentro de un plazo de 5 días contados desde su notificación, acción que se sustanciará conforme a la tramitación prevista para los incidentes en el Código de Procedimiento Civil ${ }^{59}$, no pudiendo resolverse de plano. Asimismo, cabe agregar que dentro del mismo plazo las partes pueden solicitar informes de peritos.

Finalmente, si la gravedad de las circunstancias lo amerita, el Tribunal puede disponer provisoriamente, como medida precautoria ${ }^{60}$, un equipo de emergencia.

De esta manera, a la luz de la doctrina de los órganos de control de la OIT antes analizada, se advierte que el concepto utilizado en nuestra legislación respecto a los servicios mínimos, al igual que en el caso de los servicios esenciales, podría abarcar otros servicios que van más allá de lo señalado por el Organismo Internacional.

A su vez, en la actual legislación no se contempla el conocimiento anticipado de los servicios mínimos por parte de los trabajadores ni del empleador respectivo, sino que se regula sólo una vez producida la huelga y previa solicitud de la parte empleadora. Asimismo, la regulación del procedimiento en caso de negativa de la comisión negociadora o de discrepancia, no protege ni hace efectiva realmente la posibilidad de establecer servicios mínimos.

Ahora bien, conforme a la última indicación ingresada por el Ejecutivo al proyecto de ley que moderniza el sistema de relaciones laborales ${ }^{61}$, previo a un proceso de negociación

\footnotetext{
58 Artículo 380 del Código del Trabajo.

${ }^{59}$ Artículo 392 del Código del Trabajo.

${ }^{60}$ Artículo 393 del Código del Trabajo.

${ }^{61}$ Indicaciones al proyecto de ley que moderniza el sistema de relaciones laborales, introduciendo modificaciones

al Código del Trabajo. Boletín 9835-2013, de 12.09. 2015. Nº 935-363.
} 
colectiva, las partes involucradas deberán calificar y determinar los servicios mínimos, así como los equipos de emergencia asociados a estos.

Para tal efecto, y sin afectar el derecho de huelga en su esencia, se contempla que la comisión negociadora sindical, provea el personal destinado a atender los servicios necesarios para proteger los bienes e instalaciones de la empresa y prevenir accidentes, así como garantizar la prestación de servicios de utilidad pública, la atención de necesidades básicas de la población, la seguridad o la salud de las personas, y para garantizar la prevención de daños ambientales o sanitarios.

A fin de calificar y establecer los servicios mínimos y equipos de emergencia respectivamente, el empleador, con una antelación de 180 días al vencimiento de la vigencia del instrumento colectivo vigente ${ }^{62}$-en caso de haber más de un instrumento colectivo vigente se considerará aquel más próximo a vencer- elaborará y propondrá por escrito a todos los sindicatos existentes en la empresa los servicios mínimos que estime pertinente, calificación que tendrá que ser remitida a la Inspección del Trabajo.

De no existir sindicato en la empresa, transcurridos 15 días desde la comunicación de constitución de una organización sindical, el empleador tendrá que formular y presentar su propuesta de servicios mínimos. Período durante el cual no se podrá iniciar un proceso de negociación colectiva. Mismo efecto se aplicará, ante la no calificación de los servicios mínimos y equipos de emergencia.

Ahora bien, presentada la propuesta por parte del empleador, el o los sindicatos involucrados tendrán un plazo de 15 días para responder conjunta o separadamente, transcurrido éste tendrán un plazo de 30 días para alcanzar un acuerdo.

Alcanzado el acuerdo, se deberá levantar un acta que consigne los servicios mínimos y los equipos de emergencia, misma que deberá ser suscrita por el empleador y todos los sindicatos que concurrieron a tal calificación, copia de ésta deberá depositarse ante la Inspección del Trabajo. En caso contrario, cualquiera de las partes podrá solicitar la intervención de la Dirección Regional del Trabajo, Institución que, previo a oír a las partes y solicitar los informes técnicos o realizar visitas inspectivas, deberá resolver dicho requerimiento dentro de un plazo de 45 días. Notificada la resolución, ésta sólo será reclamable ante el Director Nacional del Trabajo, sin contemplarse expresamente en el proyecto la posibilidad de reclamar judicialmente de dicha resolución. La misma Institución, durante el mes de abril de cada año, deberá publicar los estándares técnicos que han servido de base para calificar los servicios mínimos y equipos de emergencia.

Por otra parte, respecto a la conformación de los equipos de emergencia, el empleador, en su respuesta al proyecto de contrato colectivo, requerirá a la comisión negociadora sindical, a fin de que ésta señale los trabajadores afiliados al sindicato que conformarán los equipos de emergencia destinados a atender los servicios mínimos, cuando así procediere. Luego, la

${ }^{62}$ Conforme al inciso cuarto del artículo 321 del Proyecto, "el contrato, el convenio colectivo y el acuerdo de grupo negociador deberán constar por escrito y recibirán indistintamente en este Código la denominación genérica de instrumentos colectivos". 
comisión negociadora sindical tendrá un plazo de 48 horas para responder el requerimiento del empleador, de no emitir dicha respuesta se entenderá que acepta la propuesta del empleador.

Finalmente, cabe precisar que en el caso que el sindicato no provea el equipo de emergencia, la empresa podrá adoptar las medidas necesarias para atender los servicios mínimos, debiendo informar de ello inmediatamente a la Inspección del Trabajo, con el objeto de que constate dicho incumplimiento.

De esta manera, a la luz de la doctrina de los órganos de control de la OIT antes analizada, se advierte que la regulación de los servicios mínimos, de la manera que actualmente se contempla en las últimas indicaciones ingresadas por el Ejecutivo al proyecto de ley, no se ajustarían completamente a los lineamientos de los órganos de control de la OIT. Lo anterior, considerando, entre otros aspectos, la amplitud del concepto de servicio mínimo, la falta de limitación de estos servicios a las operaciones estrictamente necesarias, el conocimiento previo que tengan las partes respecto a los servicios mínimos y la inexistencia expresa de una etapa judicial en caso de conflicto en su determinación.

\section{EL REEMPLAZO DE TRABAJADORES EN HUELGA}

\subsection{EL REEMPLAZO DE TRABAJADORES EN HUELGA EN CHILE}

En cuanto al reemplazo de trabajadores en huelga, primero se analizará la legislación nacional y luego los criterios establecidos por los órganos de control de la OIT.

De esta manera, cabe señalar que la posibilidad de que el empleador sustituya a los trabajadores que se encuentran ejerciendo el derecho de huelga se encuentra expresamente reconocida en el ordenamiento jurídico laboral chileno, concretamente en el artículo 381 del Código del Trabajo, a diferencia de lo que ocurre en gran parte del derecho comparado.

En efecto, se ha señalado que "se encuentra probibida en prácticamente todos los países de América Latina, incluso, aquéllos que comparten con Chile el modelo reglamentario restrictivo de la huelga. Así, sólo a modo de ejemplo, se encuentra probibido en Colombia (art. 449 del Código del Trabajo), Ecuador (art. 494 Código del Trabajo), México (art. 8 Ley Federal del trabajo) y Brasil (art. 7 de la ley No 7.783). En Europa, y también a modo de ejemplo, está probibido la sustitución de trabajadores en la buelga en España (art. 6.5 DRLt 17/77), Francia (art. 124-2-3 del Código del Trabajo), en Portugal (art. 6 ley de huelga). En América del Norte, a su vez, y junto al caso mexicano ya señalado, cabe señalar que probíben el reemplazo de trabajadores en huelga el Código del Trabajo de Québec-Canadá (art.109.1) e, incluso, en Estados Unidos la jurisprudencia mayoritaria considera ilegal el reemplazo permanente de trabajadores en huelgas cuando sean respuesta a prácticas desleales del empleador"63.

Si bien el artículo 381 del Código del Trabajo, en la parte inicial de su primer inciso, prohíbe de modo general el reemplazo de trabajadores en huelga, dicho precepto contempla la posibilidad de sustituir a aquellos trabajadores que estén ejerciendo el derecho de huelga, en

${ }^{63}$ Informe Anual Sobre Derechos Humanos en Chile (2008). Facultad de Derecho, Universidad Diego Portales. p.157. 
cuyo caso, y en la medida que se cumplan ciertas condiciones, se puede reemplazar desde el primer día o bien a partir del décimo quinto día de hecha efectiva la huelga.

Así, nuestra legislación establece que para que proceda el reemplazo de trabajadores en huelga, la última oferta del empleador ${ }^{64}$, que tenga lugar dentro de un proceso de negociación colectiva reglado, debe contener, a lo menos:

a) Idénticas estipulaciones que las contenidas en el contrato, convenio o fallo arbitral vigente, reajustables con el porcentaje de variación del índice de Precios al Consumidor -en adelante IPC- determinado por el Instituto Nacional de Estadísticas o el que haga sus veces, habido en el período comprendido entre la fecha del último reajuste y la fecha de término de vigencia del respectivo instrumento;

b) Una reajustabilidad mínima anual según la variación del IPC para el período del contrato, excluidos los doce últimos meses, y;

c) Un bono de reemplazo, que asciende a la cifra equivalente a cuatro Unidades de Fomento $^{65}$ por cada trabajador contratado como reemplazante. La suma total a que ascienda dicho bono se paga por partes iguales a los trabajadores involucrados en la huelga, dentro de los 5 días siguientes a la fecha en que ésta haya finalizado.

De este modo, dependiendo del cumplimiento de las condiciones previstas en la citada disposición legal, se determina la oportunidad en que el reemplazo puede tener lugar, de suerte que cumpliéndose las condiciones previstas en las letras a), b) y c) antes señaladas, el empleador está facultado para contratar trabajadores que considere necesarios para el desempeño de funciones de trabajadores en huelga, desde el primer día de haberse hecho ésta efectiva.

A su vez, los trabajadores involucrados en dicho proceso, pueden reintegrarse a sus labores a partir del décimo quinto día de haberse hecho ésta efectiva.

Luego, de no observarse las condiciones contempladas en las letras a) y b) en la última oferta del empleador, aún en dicha circunstancia, está facultado para contratar trabajadores de reemplazo, con la salvedad que, en dicho caso, el reemplazo puede tener lugar a partir del décimo quinto día de hecha efectiva la huelga, y siempre que, se ofrezca un bono equivalente a cuatro unidades de fomento por cada trabajador contratado.

Se establece, además, que si la última oferta hecha por el empleador no se realiza en la oportunidad prevista en el inciso segundo del artículo 372 del Código del Trabajo, esto es, con una anticipación de a lo menos dos días a la fecha de votación de la huelga, puede reemplazar

\footnotetext{
${ }^{64}$ De acuerdo a lo dispuesto en el artículo 370 del Código del Trabajo, se entiende por última oferta u oferta vigente del empleador, la última que conste por escrito de haber sido recibida por la comisión negociadora y cuya copia se encuentre en poder de la Inspección del Trabajo respectiva. A su vez, el artículo 372 del mismo cuerpo normativo dispone que el empleador deberá informar a todos los trabajadores interesados su última oferta y acompañar una copia de ella a la Inspección del Trabajo, con una anticipación de a lo menos 2 días al plazo de 5 días para votar la huelga. Para este efecto, entregará un ejemplar a cada trabajador o exhibirá dicha proposición en lugares visibles de la empresa. Todos los gastos correspondientes a esta información serán de cargo del empleador.

${ }^{65} \mathrm{U} \$ 160$ aproximadamente.
} 
trabajadores a partir del decimoquinto día, en la medida que dicha oferta cumpla con los requisitos expuestos en las letras a), b) y c).

Conforme a las últimas indicaciones ingresadas por el Ejecutivo al proyecto de ley que moderniza el sistema de relaciones laborales ${ }^{66}$, se contempla la prohibición de reemplazar los puestos de trabajo de los trabajadores en huelga. A su vez, se establece que la infracción a dicha prohibición constituye una práctica desleal grave, facultando a la Inspección del Trabajo a requerir el retiro inmediato de los trabajadores reemplazantes de los puestos de trabajo en huelga.

\subsection{EL REEMPLAZO DE TRABAJADORES EN HUELGA EN LA DOCTRINA DE LA} OIT

Tal como ha sido analizado, el Comité de Libertad Sindical estima que el derecho de huelga puede ser objeto de restricciones, o incluso de prohibición, únicamente ante una situación de crisis nacional aguda, o bien cuando se trate de una función pública o de servicios esenciales en un sentido estricto, y en la medida que, ésta pudiere causar graves perjuicios a la colectividad nacional ${ }^{67}$.

En este sentido, aparece de manifiesto que el reemplazo de trabajadores en huelga no se corresponde a algunas de las condiciones previstas por los órganos de control de la OIT que permitan limitar o restringir el derecho de huelga, ni mucho menos se puede asemejar a los denominados servicios minimos. De esta manera, consideramos que nuestra normativa nacional no se ajustaría a los términos planteados por los órganos de control de la OIT en esta materia.

En efecto, la Comisión de Expertos ha declarado tajantemente que la sustitución de trabajadores en huelga, regulada en nuestro país, va en contra de sus preceptos y recomendaciones ${ }^{68}$.

A su vez, el Comité de Libertad Sindical ha precisado que "el actual artículo 381 probíbe de manera general el reemplazo de los huelguistas. Sin embargo, se observa que sigue existiendo la posibilidad de proceder a dicho reemplazo mediante el cumplimiento de ciertas condiciones. El artículo actual contiene, además de las condiciones que ya existían, la del pago del bono de reemplazo a los huelguistas que vuelve más onerosa la contratación de nuevos trabajadores al empleador. No obstante, la Comisión recuerda que el reemplazo de los trabajadores menoscaba gravemente el derecho de buelga" ${ }^{\prime 29}$.

Este criterio ha perdurado en el tiempo, tal como da cuenta el análisis que realiza el Comité de Libertad Sindical en el caso No 2770 del año 2010, relativo a una queja presentada contra el Estado de Chile por la Federación Sindical Mundial, al reiterar que “... el recurso a la

\footnotetext{
${ }^{66}$ Indicaciones al proyecto de ley que moderniza el sistema de relaciones laborales, introduciendo modificaciones al Código del Trabajo. Boletín 9835-2013, de 12.09. 2015. Nº 935-363.

${ }^{67} \mathrm{La}$ libertad sindical, recopilación de decisiones y principios del Comité de Libertad Sindical del Consejo de Administración de la OIT. Oficina internacional del Trabajo, Ginebra.

${ }^{68}$ Informe Anual Sobre Derechos Humanos en Chile (2008). Facultad de Derecho, Universidad Diego Portales. p.157.

69 Ídem.
} 
utilización de mano de obra no perteneciente a la empresa con el fin de sustituir a los huelguistas, por una duración indeterminada, entraña el riesgo de violación del derecho de huelga que puede afectar el libre ejercicio de los derechos sindicales. Asimismo. El Comité observa que la Comisión de Expertos en Aplicación de Convenios y Recomendaciones (CEACR) ha señalado en varias oportunidades que el artículo 381 del Código del Trabajo no está de conformidad con el Convenio $N^{\circ} 87$ ratificado por Chile".

En razón de lo anterior, el Comité de Libertad Sindical recomienda al Estado de Chile, adoptar "medidas para modificar el artículo 381 del Código del Trabajo, de manera que la contratación de trabajadores para reemplazar a buelguistas sólo sea posible en casos de buelga en servicios esenciales en el sentido estricto del término, en caso de que no se respeten los servicios mínimos o en caso de crisis aguda, así como que se asegure que dicha modificación se aplique de manera efectiva" ".

En cuanto a las modificaciones que contemplan las últimas indicaciones ingresadas por el Ejecutivo al proyecto de ley que moderniza el sistema de relaciones laborales, consideramos que tampoco se ajustarían a los términos planteados por los órganos de control de la OIT en esta materia, toda vez que la prohibición se encuentra asociada, al menos expresamente, sólo al reemplazo de los puestos de trabajo de los trabajadores en huelga.

\section{CONCLUSIONES}

No cabe duda que la huelga es un derecho fundamental que resulta esencial para la plena vigencia del principio de libertad sindical, puesto que constituye uno de los medios esenciales de que disponen los trabajadores para promover y defender sus intereses. A su vez, permite garantizar una adecuada protección al ejercicio del derecho de asociación que gozan los trabajadores, y sobre todo a la posibilidad que finalmente puedan negociar en igualdad de condiciones con sus empleadores.

De esta manera, si bien el derecho de huelga requiere de un reconocimiento y garantía total en su ejercicio, al igual que cualquier derecho reconocido en el ordenamiento jurídico, no es absoluto e ilimitado, toda vez que debe confluir e interactuar en el sistema jurídico con diversos derechos, pudiendo limitarse o restringirse su ejercicio.

En este sentido, cualquier limitación o prohibición que pudiese afectar el derecho de huelga debe interpretarse restrictivamente. Al respecto, el Comité de Libertad Sindical ha sido categórico al señalar que la huelga puede ser objeto de restricciones, o incluso de prohibición, sólo ante situaciones excepcionales y calificadas, como lo es ante una situación de crisis nacional aguda, o bien cuando se trata de una función pública o de servicios esenciales en el sentido estricto del término.

En nuestro país, si bien el derecho de huelga no tiene una consagración expresa en la Constitución, existe cierto grado de consenso, tanto por una parte de la doctrina nacional

\footnotetext{
${ }^{70} \mathrm{Al}$ respecto, cabe tener presente las siguientes quedas presentadas en contra del Estado de Chile: Caso número 2392, presentada con fecha 14 de octubre de 2004; Caso número 2352, presentada con fecha 18 de mayo de 2014; Caso número 2141, presentada con fecha 18 de junio de 2001; Caso número 2770, presentada con fecha 27 de marzo de 2010.
} 
como por la jurisprudencia, en señalar que es un derecho constitucional implícito, además de reconocérsele el carácter de derecho fundamental.

No obstante dicho reconocimiento, nuestra legislación contempla una serie de restricciones, cuya excesiva regulación ha mermado el legítimo ejercicio del derecho de huelga, a tal punto que, en determinados sectores productivos, existe una prohibición total de su ejercicio, vulnerándose con ello la libertad sindical. De esta manera, sin considerar los cambios propuestos en el proyecto de reforma laboral -actualmente en discusión-, nuestra legislación contempla una serie de restricciones, cuya excesiva regulación ha mermado el legítimo ejercicio del derecho de huelga, mismas que no se ajustarían totalmente a los términos planteados por los órganos de control de la OIT.

En este sentido, la OIT, a través de sus órganos de control, reiteradamente ha recomendado al Estado de Chile modificar, a la luz de los tratados internacionales ratificados y que se encuentran actualmente vigente, el reemplazo de trabajadores en huelga y el derecho de huelga en los servicios esenciales. Lo anterior, dado que es deber del Estado garantizar, promover y fortalecer el efectivo ejercicio de la libertad sindical ${ }^{71}$.

Ahora bien, las últimas indicaciones ingresada por el Ejecutivo al proyecto de ley, particularmente en lo relacionado a los servicios esenciales, al reemplazo de trabajadores en huelga y a los servicios mínimos, a nuestro parecer y conforme a la consideraciones formuladas en el cuerpo del presente informe, no se ajustarían totalmente a los términos planteados por los órganos de control de la OIT.

Finalmente, no cabe sino concluir que, si la legislación contempla la opción de prohibir el reemplazo de trabajadores en huelga, la regulación que se haga del mismo, así como de los servicios esenciales y de los denominados servicios minimos, no puede significar, en la práctica, la posibilidad de mermar la eficacia de este derecho o de reemplazar trabajadores en huelga, limitando o haciendo perder eficacia al principal mecanismo de autotutela de que disponen los trabajadores.

\footnotetext{
71 Artículo 5, inciso segundo, de la Constitución: "Es deber de los órganos del Estado respetar y promover tales derechos, garantizados por esta Constitución, así como por los tratados internacionales ratificados por Chile y que se encuentren vigentes".
} 
Rodrigo Azócar Simonet Y Álvaro Cruz González / Limitaciones al derecho de buelga en Cbile: Los servicios esenciales, $e l$ reemplazo de trabajadores y los servicios mínimos en el contexto de la Reforma Laboral 


\section{BIBLIOGRAFÍA}

ERMIDA URIARTE, Óscar (1986): Apuntes sobre la buelga. (Montevideo, Fundación de cultura Universitaria).

GAMONAL CONTRERAS, Sergio (2011): El derecho colectivo del trabajo. (Santiago, Legal Publishing Chile).

GAMONAL CONTRERAS, Sergio (2013): "El derecho de huelga en la constitución chilena". Disponible en $\quad$ http://www.scielo.cl/scielo.php?pid=S071897532013000100005\&script $=$ sci arttext. $>$

GERNIGON, BERNARD; ODERO, Alberto y GUIDO, Horacio (1998): Principios de la OIT sobre el derecho de huelga. (Ginebra, Oficina Internacional del Trabajo).

IRURETA, Pedro (2015): "Constitución y Orden Público Laboral, Santiago". Disponible en <http://www.derecho.uahurtado.cl/documentos/coleccion_investigaciones_juridicas.pdf>

MACCHIAVELLO, Guido (1989): Derecho colectivo del trabajo. (Santiago, Editorial Jurídica de Chile).

MANTERO ÁLVAREZ, Ricardo (1992): Limites al derecho de buelga. (Montevideo, Ediciones jurídicas Amalio M. Fernández).

OFICINA INTERNACIONAL DEL TRABAJO (2015): “La libertad sindical, recopilación de decisiones y principios del Comité de Libertad Sindical del Consejo de Administración de la OIT" Disponible en <http://www.ilo.org/public/spanish/bureau/leg/download/digest_cfa.pdf. >

SALA FRANCO, Tomas (2013): Derecho Sindical. (Valencia, Editorial Tirant lo Blanch).

UGARTE CATALDO, José Luis (2014): “La huelga en el derecho laboral chileno: superando el espejismo" Disponible en http://www.jornadasdeltrabajo.cl/wpcontent/uploads/2014/09/Jose-Luis-Ugarte-El-Concepto-de-Huelga-en-el-DerechoChileno.pdf.

UNIVERSIDAD DIEGO PORTALES (2015): “Centro de derechos humanos "Disponible en <http://www.derechoshumanos.udp.cl/derechoshumanos/index.php/informe-anual/funcstartdown $/ 263 />$ 


\section{JURISPRUDENCIA ADMINISTRATIVA}

Inspección Comunal del Trabajo Santiago sur Orientge con Comercial Promolinks S.A. (2014): Corte Suprema, 04 de diciembre de 2014 (Recurso de unificación de jurisprudencia), Legal Publishing.

\section{JURISPRUDENCIA JUDICIAL}

Actionline Chile S.A. con Yutronic (2015): Corte de Apelaciones de Santiago, 23 de octubre de 2015 (Recurso de nulidad), Legal Publishing.

\section{NORMAS CITADAS}

Constitución Política de la República de Chile.

Código del Trabajo

Convenio $\mathrm{N}^{\mathrm{o}} 87$, sobre la libertad sindical y la protección del derecho de sindicación, ratificado por Chile el 01 de febrero de 1999.

Convenio 98, sobre el derecho de sindicación y de negociación colectiva, ratificado por el Chile el 01 de febrero de 1999.

Pacto de Derechos Económicos, Sociales y Culturales, ratificado por Chile el 28 de abril de 1989. 